\title{
A REVIEW ON DESIGNING A EUROPE WIDE BIG SCALE PILOT FOR THE IOT IN THE AGRICULTURE
}

\begin{tabular}{|c|c|c|c|}
\hline \multicolumn{4}{|c|}{$\begin{array}{l}\text { N.N.Saxena } \\
\text { rsity, Mathura }\end{array}$} \\
\hline Journal & \multicolumn{3}{|c|}{$\begin{array}{l}\text { Samvakti Journal of Research in Information Technology } \\
\text { https://www.sjirit.samvaktijournals.com } \\
\text { Volume } 2 \text { Year of Volume } 2021 \text { Page No : } 24 \text { - } 32\end{array}$} \\
\hline Discipline & \multicolumn{3}{|l|}{ Internet of Things } \\
\hline Conference & \multicolumn{3}{|c|}{$\begin{array}{l}\text { A virtual international conference on redefining and transforming the role of higher } \\
\text { education in sustainable development }\end{array}$} \\
\hline Conference & \multicolumn{3}{|c|}{ Start Date: September 30, 2021} \\
\hline Dates & \multicolumn{3}{|c|}{ End Date : September 30, 2021} \\
\hline Institute Name & \multicolumn{3}{|c|}{$\begin{array}{l}\text { JAIN (Deemed-to-be University) in association with Council for Industrial } \\
\text { Innovation and Research }\end{array}$} \\
\hline $\begin{array}{l}\text { Date Received } \\
\text { ID } \\
\text { Dol }\end{array}$ & $\begin{array}{l}\text { November } 19,2021 \\
: 2021.02 .13 \\
10.46402 / 2021.02 .13\end{array}$ & $\begin{array}{l}\text { Publication Date } \\
\text { Paper Type } \\
\text { Dol URL }\end{array}$ & $\begin{array}{l}\text { : December 11, } 2021 \\
: \text { Conference Paper } \\
: \text { https://dx.doi.org/10.46402/2021.02.13 }\end{array}$ \\
\hline
\end{tabular}

\section{ABSTRACT}

The Internet of Things technologies have a lot of promise for use in the food and agricultural sector, particularly given the social and environmental problems that this industry faces. IoT technologies have the potential to revolutionize the food industry from farm to fork, contributing to food safety, agricultural input reduction, including food waste reduction. The implementation of the loT based large scale pilots throughout the whole supply chains will be a significant step toward wider adoption of these technologies. The difficulties and limitations that an LSP implementation of IoT in this area must address are outlined in this article. In the order to establish a sets of the technical or agro food's needs, sectoral and technological problems are outlined. We quickly describe an architecture based on system of systems approaches, emphasize the significance of solving the sector's interoperability problems, and discuss needs for new privacy, business model, security, including data governances. Finally, a summary of the technology and solutions used in pilot design for four agri-food domain (dairy, fruits, 
arable, meats, or vegetable supply chains) is given. Finally, it should be emphasized that for loT to succeed in this area, a major cultural shift is required.

KEYWORDS: Agriculture, Agri-Food, IoT Technologies, LSP, Supply Chain.

\section{INTRODUCTION}

Internet of Thing offers once-in-a-lifetime chance for technology to revolutionize a variety of sectors, including food and agriculture. The agri-food industry has lower rate of adoption of the information's or communication technology or high data collection costs. Sensors, navigation systems, actuators, drones, clouds based data service, or analytics offer a range of decisions support capabilities, and the loT stack of technologies may substantially alter this industry. The European Commission will finance large scale deployment, and pilot of the loT throughout Europe as part of H2020. This article offers a review of possible roles of Internet of things in agri food industry since the viewpoint of building and defining the loT constructed LSP, allowing readers to grasp the possibilities, limitations, and needs that loT may solve in the sector. loT technology are referred to as precisions agriculture and "smarts farming" in the agri food industry. The usage of the GPS to operate tractor (automobile guidance's of the equipment) to guarantee exact coverages of fields, whether plowing, planting, and engaged in another activity, is a good example. The increasing instrumentation of the agri food industry results in a plethora of innovative data driven services. These may tell a farmer when to spray and apply fertilizers, whenever the inseminates dairy herd, or when to collect information needed by the supervisory and certifying organizations. Information drive service might benefits logistic or supply chains by allowing for better routes planning, easing recalls in food crisis situations, and enhancing stock taking and ordering procedures in general. Data from supermarket checkout counters and loyalty cards may be the easily integrated into different IoT eco-system components. The bulk of this technology or services exists, although they are only used in a few situations ${ }^{[1]}$.

\section{The Agri-Food Industry's loT Challenges and Constraints:}

There are significant barriers to loT adoption in agriculture, but there are also unique motivations. Large scales industrials farming, particularly in the North America, or supermarkets in the most industrialized nations have adopted ICT or related data driven service. Even in highly developed nations, there are numerous regions where loT adoption is low or non-existent. The following sections go over the major problems influencing loT adoption in the European agri-foods industry. 


\section{Sectoral Concerns:}

\section{a. Sector heterogeneity:}

The food system has a wide range of various kinds of players, from the very big (supermarkets) to the extremely tiny (seed companies) (artisanal cheeses maker, roadsides fruits, microbreweries, or vegetables seller). As a result, no one solutions, whether technical, business model, as well as regulatory, can meet everyone's requirements. Vineyard in the Hungary needs quites dissimilar solution than the arable farmer in the United States. Precisions agricultural techniques in arable farming, for example, have been extensively embraced by big farmer in the Central or Northern Europe's to boost output or improve quality in the EU. In the Southern Europe, however, recent economics pressures in agriculture, higher farm segmentation or dispersions, as well as growing water shortages, need the use of precisions irrigation methods, primarily to reduce resource use.

Suitable business model with required degree of secrecy or controls over information are required, while also enabling farms and other agri-food players to monetize the data they produce. This is a point of controversy, with big companies like as John Deere attempting to profit from the data collected by equipment they sell, while farmers view it as alternative losses of the controls or values. The Agricultural Data Coalition was recently formed by Americans Farms Bureau Federations, which has been spearheading battle for the farmer to the maintain controls or ownerships of their information ${ }^{[2]}$.

\section{b. User and social acceptance:}

Consumers must be educated and trained in order to comprehend how to utilize and use these novel technology. According the $71.001 \%$ of the EU farms manager, they were stills working on basis of the practical's experiences untils in recent times, thinking the such improvements were unnecessary for their daily duties and that they did not have time to the learns. Adoptions of smart technology will certainly be the difficult for those who are not digitally savvy. However, there are currently education and training programs in place throughout Europe to spread loT culture among young people and other food chain players.

\section{c. Technological Challenges Interoperability issues:}

For billions of devices to communicate, common buildings block, data protocol, or standard are required, and there are many suitable standards in the agri-food sector in an effort to achieve an overall agreement in this field. There are standards for semantic or data modeling ( Agro RDF, Agro VOC, and agro XML), Agri equipment ( ISOBUS), weathers information (e.g. SWEETs), the supply chains (like EPCIS from the GS1), e 
commerce's retails store (like Good Relation or Schema org), or numerous initiative (e.g., IEEE Standard Association lo)

\section{d. Lack of connection:}

Lack of connectivity, or inadequate third or fourth generations (3G or 4G) coverages, is a major barrier to the continued growth of loT in agriculture in many places (in spites of more trumpet wish to the moves to the 5G). Lower powers wides area technology like as Lo Ra or SIGFOX provides a genuine chance to get over these restrictions [9], but they can't manage big datasets.

\section{e. Data processing power:}

It may come as a surprise, but for small to medium farms, accessing large scales processing power at reasonables costs to perform complicated computations (like traveling salesman types field traversal planning's) remain a problem. IoT is severely hampered by the lack of data processing services ${ }^{[3]}$.

\section{f. Lack of a defined data governance framework:}

Regulation or legal framework is still catching to contemporary technology realities. The ownership and control of agricultural data is still a point of contention. Large corporations might wish to the think of the themselves data businesses or oppose efforts that would give farmers and other main players ownership of data.

\section{g. Security and privacy of data:}

Security or data privacy concerns are distinct from the governance concerns. The tops five worries amongst respondents directly and indirectly relates to the security \& privacy, according to European Commissions Morldwide Information Corporations study of the EU demands for clouds computing facilities or obstacles to the adoption. This demonstrates the broader significance of such issues for loT adoption in smart agriculture.

\section{Architecture in general:}

There are already a number of "precision agriculture" systems and platforms in use, which use a range of communication, sensor, and data processing technologies. And due to the possible scalability (preserving states in the pub or sub methods) or governances (access to agricultural data) problems, the strategy of creating novel masters system to integrate others might not be viable for an LSP. As a result, a systems of systems strategy is suggested. This allows current agricultural knowledge information's system to the continue to operate while also allowing such systems to makes data from the cooperating systems insides the SoS accessible and consumed. In addition, the SoS may inform 
collaborating AKISs about fresher technologies or services that might be of interests. In terms of usability, market acceptance, or long term viability, this is more feasible. The suggested solution must meet the following two basic functional criteria in order to implement this strategy. Allow current AKISs to exchanges data with and consume data from their peers. Virtualizations container for the services should be used extensively to enable fast deployments when needed. The suggested architecture includes an incoming or out bounds facilities that allows AKIS to the expose or consumes information. Survey facilities that do not need a constant feed from a specific AKIS would benefit greatly from rapid deployment. like as service would install and start an incoming service for that specific AKIS, collect the required data, and then terminate the service. The facility will be the packed in lightweights containers that includes all of the software required for self's contain deployments (runtime environments, libraries for the support communication protocol, encryptions techniques) $)^{[4]}$

Addressing Interoperability Issues: In the agricultural sector, interoperability is a major concern. A hardware supplier from the countries should able to the deliver services to the farmer in the country B utilizing software's from the country $C$ in order for a sustainable ecosystem to emerge. Gateway, an organization of agricultural and attach businesses based in the United States but growing worldwide, is perhaps the most well-coordinated domain specific initiative in this approach. Technical interoperability is not covered in this section because the protocols and infrastructures require are not specifics to agri-food industry. Instead, domain agnostic organizations such as the Open Channel Foundation (OCF) are addressing the issue with initiatives like the Alliance for Internets of the Things Innovation, which was established to fosters dialogue among Europe's several actors ${ }^{[5]}$.

\section{Interoperability in Syntax:}

Despite the broad use of the XML or more in recent times, JSON as the standard syntaxes for the data exchange, it is frequently more convenient to exports in basic forms such comma separate variables due to the vast range of older systems (CSV). Despite its cost and complexity, electronic data exchange (EDI), particularly EDIFACT, continues to play a major role in certain agri food industries, primarily for invoicing and related kinds of communications. As a result, all systems must offer exports facilities \& API access that the returns standard format, such as XML or JSON, \& older systems must be supplied with suitable interchanges gateways whenever feasible.

\section{Other Important Pilot Specifications Factors:}

\section{a. Business Models of the Future:}

The food chain is rapidly becoming a food-and-data chain. Despite the fact that there have been slew of data driven startup in the agri food sector in recent years, the industry 
is being transformed by big companies. Various data focused companies have been purchased by DuPont, Monsanto, and John Deere. Because the dominant stakeholder are nowadays establishing powerful position for the themselves, there might be little incentives to he enable radicals, transformative changes, or recents development will not fully exploit the benefits of smarts technologies and explores new ways to connect parties in the supply chains. Engaged farmers will become active prosumers of agri data rather than the passives consumer of the information processed by the others in the future of farming. As a result, novel connected collaboratives agriculture farming's paradigm is required, with the farmers serving as the main source of the agricultural information ${ }^{[6]}$.

\section{Privacy and Security:}

Despite the emergence of various global initiative in the recents years, including the Internationals Recycles Congress ITU Telecommunication Standardizations Sector Research Groups 20 (S G20), and the IEEE Internet of thing Initiatives, as well as the Internet Protocols Protections Option Alliance, there is stills lacks of united visions on user confidentiality consideration in loT. Data confidentiality including authentication, access controls inside the loT networks, confidentiality or trust among users or objects, and the implementation of the security or privacy rules are all requirements for the agri food sector.

\section{Ownership and Governance of Data:}

The suggested method is to make sure that the design allows the main data producer to have full control over the data (i.e., the farmer, the transportations company, and the aggregators). This would provides participants in an loT ecosystem a feeling of autonomy, while simultaneously complying with the Europeans Data Protections Regulation's privacy standards or allowing farmer to use data as possible sources of revenue. Farmer have typically lost out the in recents years as a result of changes in the agri-food supply chain, so having ownership of data and being able to view it as a source of revenue are significant motivations to join the loT ecosystem.

\section{Pilots at a Large Scale:}

The goal of an LSP is to assess the usability or utility of the Internet of Things technology in the agricultures, or four pilot domain have been suggested. The primary emphasis, the technical difficulties tackled, the loT technologies utilized, and the agri-food applications offered are all described. The last part includes a set of measures for quantitatively evaluating the planned pilots. Several sample applications from the four pilot domains are shown $^{[7]}$. 


\section{The main emphasis of the Dairy Pilot is:}

Representing end to end integration of diverse data source through the value chain, as well as enhanced farm decision-making. Piloting Fruit Demonstrating interoperability of the Internet of things systems or supports for the advanced learning, reasoning, or predictions across a variety of farm-related components is the main goal Device /sensor for air/ soils/water monitoring ( evapotranspirations water holding capacity, stems water potential, stems instrument sensors, CO2 gas, IR and VIS absorbance or temperatures, water nitrate as well as conductivity, radiations, nutrients level, humidity, $\mathrm{pH}$, cation exchanges capacity, as well as salinity), sun power, winds (direction or peed), and meteorological station network) are all examples of loT HW/ Agri-machinery surveillance (sensor monitoring through the ISOBUS, temperatures, pressure, electronic noses, products barcode reader, RFID sensor, irrigations systems supervisory solenoid valves or hydrometer, fertigation's actuator, self-directed solars unit) ${ }^{[8]}$.

\section{Pilot Program for Meats or Vegetable Main focus:}

Demonstrating the interconnection of different stakeholders' Internet of Things system throughout the entire food supply chains, elements monitoring or tracking across all the supply chains stages, and data security or privacy. HW/SW for Internet of Things for Meat, it's similar to Dairy Pilots, and for Vegetables, it's comparable to the Fruit Pilots. RFID readers RFID tags, slaughterhouse recorders (monitoring information's on the deaths time/origins of the animals or safety compliances), or sensor for the recordings vehicle movements are among the other devices/sensors. Temperature, humidity, luminosity, $\mathrm{CO} 2$, noise, or ammonia sensors for the farms or vehicles, as well as weight/loads cell and cooling actuators (transports or shop shelve). Communications technologies comparable to those used in the Dairy pilots as well as vehicles to infrastructure, vehicleto-vehicle, Internet of things, and Internet of Things machine to machine communications protocols (DSRC is one of the technologies utilized for V2X communications) ${ }^{[9][10] .}$

\section{DISCUSSION}

This paper is intended to help industry stakeholders and academics who are working on large-scale agricultural pilots that rely significantly on loT technology. The agri-food sector's loT-related difficulties and limitations, as well as the main goals of loT-based LSPs, are discussed. The use of a systems of system architectural approaches is suggested, with a focus on the interoperability, which is essential for adoptions of Internet of Things technology in the agri food industry. Implementing like as LSPs will certainly promotes the use of the Internet of Things in the agricultures, thus enhancing several procedure throughout the whole foods supply chains, resulting in the reduce farmer efforts or cost, better foods quality or safety and more consumer foods awareness. However, 
cultural change is desirable to realize the advantage or opportunities provides by loT technology before it is extensively utilized by stakeholder's crossways the food supply chains.

\section{CONCLUSION}

Given the social and environmental issues that this business confronts, Internet of Things technology hold a lot of potentials for applications in food or agriculture sectors. IoT technologies have the ability to transform the food sector from farm to fork, improving food safety, reducing agricultural inputs, and reducing food waste. Implementing loT based larger scales pilots throughout the whole supply chains will be major steps toward broaders adoption of these technologies. To solve semantic interoperability, the Agricultural Information's Model methodology is recommended, as well as a farm to forks management's information's systems solutions that ensures data compatibility. Many difficulties remain, including's the needs for the novel business model, safety or privacy, or information governances or ownerships solutions, all of which are essential for implementing Internet of Things based LSPs in the agri food sectors. Finally, a comprehensive description of the most suitable Internets of Things technology or agri food uses to be utilized is provided, and the major main performances indicator that can be used to assess the success of propose LSPs in the measurable way. The implementation of such as LSPs would certainly encourage the use of Internet of Things in agriculture, thus improving different activities throughout the whole foods supply chain, resulting's in decreased efforts or cost for farmers, improved food quality and safety, and more consumer food awareness. However, the primary hurdle to the overcome earlier Internet of Things is widely used by the stakeholder throughout the foods supply chains is a cultural shift that is required to recognize the benefits and possibilities offered by loT technology. 


\section{REFERENCES:}

[1] G. Witjaksono, A. A. Saeed Rabih, N. B. Yahya, and S. Alva, "IOT for Agriculture: Food Quality and Safety," 2018, doi: 10.1088/1757-899X/343/1/012023.

[2] M. S. Mekala and P. Viswanathan, "A Survey: Smart agriculture loT with cloud computing," 2017, doi: 10.1109/ICMDCS.2017.8211551.

[3] V. Porkodi, D. Yuvaraj, A. S. Mohammed, M. Sivaram, and V. Manikandan, "IoT in agriculture," J. Adv. Res. Dyn. Control Syst., 2018, doi: 10.48175/ijarsct-1351.

[4] E. Y. T. Adesta, D. Agusman, and Avicenna, "Internet of things (IoT) in agriculture industries," Indones. J. Electr. Eng. Informatics, 2017, doi: 10.11591/ijeei.v5i4.373.

[5] A. Rojas, "Smart Agriculture loT with Cloud Computing," Rev. Hist. América, 2015.

[6] M. Stočes, J. Vaněk, J. Masner, and J. Pavlík, "Internet of things (loT) in agriculture - Selected aspects," Agris On-line Pap. Econ. Informatics, 2016, doi: 10.7160/aol.2016.080108.

[7] R. Dagar, S. Som, and S. K. Khatri, "Smart Farming - IoT in Agriculture," 2018, doi: 10.1109/ICIRCA.2018.8597264.

[8] N. Ahmed, D. De, and I. Hussain, "Internet of Things (IoT) for Smart Precision Agriculture and Farming in Rural Areas," IEEE Internet Things J., 2018, doi: 10.1109/JIOT.2018.2879579.

[9] C. S. Nandyala and H. K. Kim, "Green loT Agriculture and Healthcare Application (GAHA)," Int. J. Smart Home, 2016, doi: 10.14257/ijsh.2016.10.4.26.

[10] V. N. Malavade and P. K. Akulwar, "Role of loT in Agriculture," Natl. Conf. "Changing Technol. Rural Dev., 2016. 